\title{
The Effects of Cirsium japonicum on Lipid Profile in Ovariectomized Rats
}

\author{
Hyeok-Yi Kwon', Mee-Ra RHYU², and YoungJoo LeE, ${ }^{1}$ \\ ${ }^{1}$ College of Engineering, Institute of Biotechnology, Department of Bioscience and Biotechnology, \\ Sejong University, Seoul 143-747, Republic of Korea \\ ${ }^{2}$ Food Function Research Division, Korea Food Research Institute, Gyeonggi-Do 463-420, \\ Republic of Korea
}

(Received June 24, 2008; Revised July 21, 2008; Accepted September 18, 2008)

\begin{abstract}
Cirsium japonicum water extracts has been used to treat vascular related diseases. We have previously reported that Cirsium japonicum extracts activated estrogen receptors. It is widely known that estrogen increases the high density lipoprotein cholesterol and decrease the low density lipoprotein cholesterol on the lipid profile. But effects of Cirsium japonicum on lipid profile are not reported yet. Therefore, we have studied the effects of Cirsium japonicum on the lipid content in ovariectomized rats. Thirty Sprague-Dawley (SD) rats of 210 $\pm 20 \mathrm{~g}$ were studied for 10 weeks. The rats were divided into five groups; (I) sham, no ovariectomized rats plus olive oil, (II) ovariectomized rats plus olive oil, (III) ovariectomized rats plus $0.5 \mathrm{mg} / \mathrm{kg} 17 \beta$-estradiol (E2) in olive oil, (IV) ovariectomized rats plus $0.5 \mathrm{mg} / \mathrm{kg}$ Cirsium japonicum in olive oil, and (V) ovariectomized rats plus 5 $\mathrm{mg} / \mathrm{kg}$ Cirsium japonicum in olive oil. Treatment with Cirsium japonicum or E2 induced significant reduction in total cholesterol, low density lipoprotein cholesterol/total cholesterol, total cholesterol/high density lipoprotein cholesterol and low density lipoprotein cholesterol/high density lipoprotein cholesterol compared to control group as well as increase in uterine weight. However, changes in triglycerides levels were different. Our results suggest that Cirsium japonicum is functionally similar to E2 in vivo as well as in vitro.
\end{abstract}

Key words: Cirsium japonicum, Lipid profile

\section{INTRODUCTION}

Cirsium species (family Compositae), generally known as thistle, are important components of traditional Chinese medicine, which is becoming increasingly popular in the Western world (Ganzera et al., 2005). The word "cirsium" derives from the Greek word meaning "swollen vein" (http://en.wikipedia.org/wiki/cirsium). Cirsium species have been used to treat edema, bleeding, hemoptysis, inflammation, and varicose veins (Lee et al., 2002). Some species are galactogues, containing a substance that increases lactation (http://en.wikipedia.org/wiki/cirsium). Additionally, flavonoids (hispidulin-7-neohesperidoside, linarin, pectolinarin, luteolin), triterpenes, wax, polyolefins, and some widespread acetylenes have been

\footnotetext{
${ }^{*}$ Corresponding author

Tel: +82-2-3408-3640, Fax: +82-2-3408-4334

E-mail: yjlee@sejong.ac.kr
}

reported from Cirsium species (Lee et al., 2002; Yim et al., 2003). Cirsium tenoreanum is used for the treatment of varicose veins. As Chinese traditional medicine has become more popular and widely used over recent years, it is vital to identify and control the quality of the herbal material employed in the treatment preparations.

Studies have shown that menopause is associated with an increased risk of coronary heart disease as a result of changes in lipid profile, clotting and fibrinolytic factors, and function of vessels all of which are likely to be caused by the loss of estrogen protection (Colacurci et al., 2005). To relieve menopausal symptoms such as hot flushes and provide various protections, estrogen replacement therapy has been used for more than 30 years and combined estrogen progesterone therapy has been widely used for at least 20 years (Glazier et al., 2001). However, adverse effects such as vaginal bleeding, breast cancer and the concept of interfering with a "natural' process are concerns in continuous using synthetic estrogen (Ravnikar, 1987; Cooper et al., 1992). As a con- 
sequence, there has been a rapid increase in consumers' interest in using alternative medicines, particularly in the use of supplements and herbs for the treatment of menopausal symptoms (Eisenberg et al., 1998).

We have previously showed that circium japonicum contains phytoestrogenic components in in vitro assays. Estrogen is well known to influence many physiological functions, such as reproduction, bone integrity, cardiovascular and neuronal systems (Deroo et al., 2006). It is known to have protective role on the regulation of lipid and cholesterol levels. Here, in this study, we aimed to study the estrogenic effect of circium japonicum on the lipid profile using ovariectomized (OVX) rats as a model system.

\section{MATRIALS AND METHODS}

\section{Plant extracts}

The dried Cirsium japonicum was obtained from a local market and ground with a commercial food mixer. This powder was consecutively extracted under reflux with water for $2 \mathrm{~h}$. The resulting water extract was evaporated under reduced pressure at low temperature (37-40 ${ }^{\circ} \mathrm{C}$ ) and lyophilized. The solid was stored at $-20^{\circ} \mathrm{C}$ until use. Solution was prepared with distilled water at a concentration of $100-300 \mathrm{mg} / \mathrm{ml}$ on the day of experiment. A voucher specimen No. CP-001 has been deposited in the Korea Food Research Institute, Gyeonggi-Do, Korea.

\section{Reagents}

$17 \beta$-estradiol (E2) was purchased from Sigma (St. Louis, MO). E2 was dissolved in $100 \%$ ethanol. All the compounds were added to the medium such that the total ethanol concentration was never higher than $0.15 \%$. An untreated group served as a control.

\section{Animal}

Eight weeks-old female Sprague-Dawley rats were purchased from Koatech, Pyoung-taek, Gyeonggi-Do, Korea. At the end of the 10 weeks experimental period, animals were 18 weeks. The animals were kept at a temperature of $23 \pm 2^{\circ} \mathrm{C}$ with a $12 \mathrm{~h}$ light and dark cycle and allowed free acess to food and water. The food provided was a proprietary formulation (Superfeed Co, Won-ju, Gangwon-do, Korea). The study was carried out on five groups of animal each consisted of six rats. Four groups of rats were ovariectomized and one group of rats were used as a sham group. For 5 weeks every day, rats were orally injected with E2 $(0.5 \mathrm{mg} / \mathrm{kg}$, in olive oil), Cirsium japonicum $(0.5 \mathrm{mg} / \mathrm{kg}$ or $5 \mathrm{mg} / \mathrm{kg}$, in olive oil) or olive oil as a control. Drug administrations were carried out according to the weekly weight measurements. Group $1(n=6)$ non OVX rats were sham-operated. The uteri were dissected out to measure their weight and used to show the intergroup differences.

\section{Plasmids}

ERE2-tk81-luc constructed by inserting the fragment of the herpes simplex thymidine kinase promoter and two copies of the vitellogenin estrogen responsive element (ERE) into pA3luc (Gehm et al., 1997) was a kind gift of Dr. Larry Jameson. Expression vector for $E R \alpha$ and $\beta$ were from Dr. Pierre Chambon and Dr. Vincent Giguere, respectively.

\section{Cell cultures}

HEK 293 cells were maintained in phenol red-free Dulbecco's modified Eagles medium (DMEM) containing $1 \times$ antibiotic/antimycotic mix (Invitrogen, Gaithersburg, MD), and $0.37 \%$ sodium bicarbonate, supplemented with $10 \%$ fetal bovine serum (FBS) (HyClone Laboratories, Inc.). Cells were grown at $37^{\circ} \mathrm{C}$ in a humidified atmosphere of $95 \%$ air $/ 5 \% \mathrm{CO}_{2}$ and fed every 2-3 days. Before hormone induction, the cells were washed with phosphatebuffered saline (PBS) and cultured in DMEM $/ 5 \%$ charcoal-dextran stripped FBS (CD-FBS) for 2 days to eliminate any estrogenic source before treatment. All treatments were done with DMEM/5\% CD-FBS. $10 \mathrm{nM}$ E2 was used to maximize the response unless otherwise noted.

\section{Transient transfection and luciferase assays}

HEK 293 cells were seeded in 24-well plates at a density of $5 \times 10^{4}$ cells/well. After $24 \mathrm{~h}$, plasmids were transiently transfected into the cell by calcium phosphateDNA coprecipitation method. A total of $0.5 \mu \mathrm{g}$ of DNA in $25 \mu \mathrm{l}$ of $\mathrm{CaCl}_{2} \cdot \mathrm{H}_{2} \mathrm{O}(250 \mathrm{mM} \mathrm{CaCl})$ was mixed with 25 $\mathrm{ml}$ of $2 \times \mathrm{HBS}(280 \mathrm{mM} \mathrm{NaCl}, 10 \mathrm{mM} \mathrm{KCl}, 1.5 \mathrm{mM}$ $\mathrm{Na}_{2} \mathrm{HPO}_{4} \cdot 2 \mathrm{H}_{2} \mathrm{O}, 12 \mathrm{mM}$ dextrose, $50 \mathrm{mM}$ HEPES) with constant bubbling and within 5 to $10 \mathrm{~min}$ this solution was added to each well. The next day, transfected cells were washed with PBS, and treated with compounds. Luciferase activity was determined 24 or $48 \mathrm{~h}$ after drug treatments with an AutoLumaat LB953 luminometer using the luciferase assay system (Promega Corp., Madison, WI) and expressed as relative light units. The mean and standard errors of the mean (SEM) of triplicate or quadruplicate samples are shown for representative experiments. All transfection experiments were repeated three or more times with similar results. 


\section{Statical analysis}

Values shown represent mean \pm SD. Statistical analysis was performed by Student's $t$ test with a $P$ value of less than 0.05 being considered statistically significant.

\section{RESULT}

\section{Cirsium japonicum activates estrogen-responsive luciferase genes in the presence of either $E R \alpha$ or ER $\beta$}

We have previously shown that Cirsium japonicum extracts activated estrogen receptors (Park et al., 2008). Some phytoestrogens such as genistein and coumestrol differ in their activity on $E R \alpha$ and $E R \beta$. We investigated whether there is a differential activation of these two receptor isoforms in response to Cirsium japonicum by examining the transcription of an ERE-containing reporter plasmid in the presence of ER $\alpha$ or ER $\beta$ in ER-negative HEK 293 cells. In the presence of the ER $\alpha$ isoform, Cirsium japonicum activated luciferase expression driven by the ERE. This activation was approximately 2 fold, as compared to untreated cells (Fig. 1A); in addition, an approximately 2.5 fold induction of the response was seen with the ER $\beta$ isoform (Fig. 1B). These data shows that Cirsium japonicum activates both $\mathrm{ER} \alpha$ and $\mathrm{ER} \beta$ isoform.

\section{Cirsium japonicum extracts affect the body and uterus.}

It has previously been shown that E2 increase high density lipoprotein cholesterol (HDLC), trigryceride, and height growth and decrease low density lipoprotein cholesterol (LDLC), and fat deposition (http://en.wikipe-
dia.org/wiki/Estrogen). In order to examine whether Cirsium japonicum affects lipid, and lipoprotein as E2, we used OVX SD rats as a model system. Body weight was increased in all OVX groups but not in E2 group. The body weight was decreased as compared with the control group in Cirsium japonicum and E2 groups (Fig. 2).

To evaluate the impact of ovariectomy, E2 $(0.5 \mathrm{mg} / \mathrm{kg})$, and Cirsium japonicum ( $0.5 \mathrm{mg} / \mathrm{kg}$ or $5 \mathrm{mg} / \mathrm{kg}$ ) dietary feeding on uterine growth, we measured the uterine weight following the 5 weeks feeding period. The uterine weights were $2.96 \pm 0.55 \mathrm{~g} / \mathrm{kg}$ body weight in sham group;

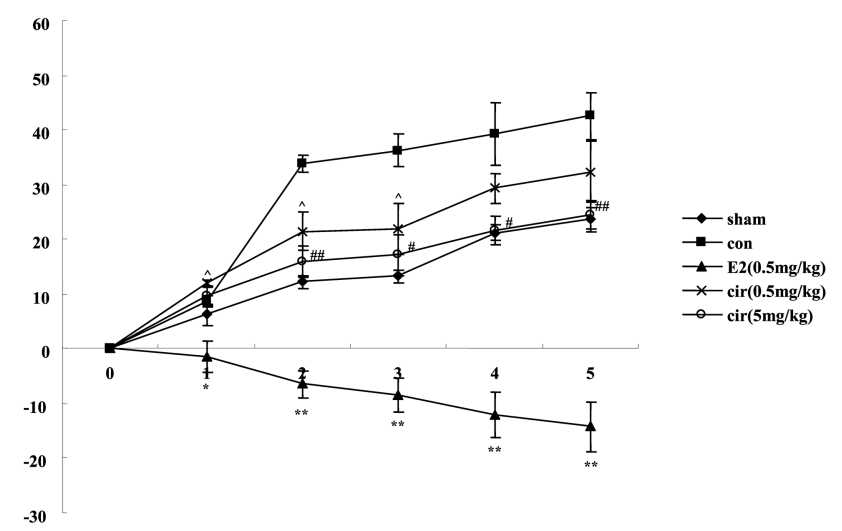

Fig. 2. Effect of Cirsium japonicum extracts on body weight. SD rats were ovariectomized. After 4 weeks, weight of operated rats were measured every week. Rats were orally injected with compounds for 5 weeks as indicated in the figure. Treatment groups are: sham (- -$)$, control (- - -), E2 0.5 $\mathrm{mg} / \mathrm{kg}(-\triangle-)$, cirsium japonicum extracts $0.5 \mathrm{mg} / \mathrm{kg}(-\bigcirc-)$ and cirsium japonicum extracts $5 \mathrm{mg} / \mathrm{kg} \quad(-\times-)$. ${ }^{\mathrm{p}} \mathrm{p}<0.05$ and ${ }^{\wedge} \mathrm{p}<0.001$ (cir $0.5 \mathrm{mg} / \mathrm{kg}$ ); ${ }^{\#} \mathrm{p}<0.05$ and ${ }^{\# \#} \mathrm{p}<0.001$ (cir $5 \mathrm{mg} / \mathrm{kg}$ ); * $p<0.05$ and ${ }^{* *} p<0.001$ (E2 $5 \mathrm{mg} / \mathrm{kg}$ ) vs OVX control group.
A.

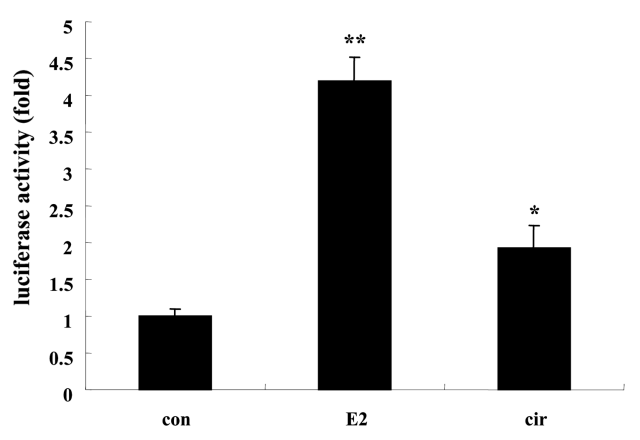

B.

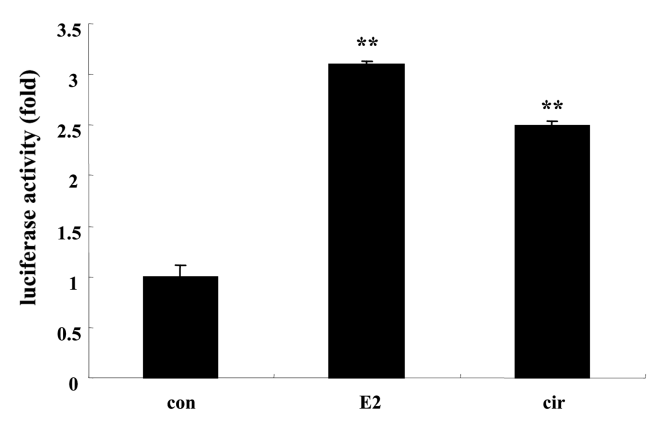

Fig. 1. Cirsium japonicum-induced transactivation was assessed by cotransfection of the ERE-luciferase with either $E R \alpha(A)$ or $E R \beta$ (B) expression plasmids in HEK 293 cells. Cell extracts were prepared and analyzed using a luciferase assay. Cells were exposed to E2 $(10 \mathrm{nM})$ or Cirsium japonicum $(200 \mu \mathrm{g} / \mathrm{ml})$ for $24 \mathrm{~h}$. The data are representative of at least three independent experiments, performed in triplicate, with similar results, expressed as relative luciferase units and the SEM of the triplicate samples. The asterisk and ${ }^{* *}$ shows a statistically significant difference from control at $p<0.05$ and 0.001 . 
$0.51 \pm 0.18 \mathrm{~g} / \mathrm{kg}$ body weight in control group; $2.30 \pm 0.29 \mathrm{~g} /$ $\mathrm{kg}$ body weight in E2 $0.5 \mathrm{mg} / \mathrm{kg}$ group; $1.64 \pm 0.38 \mathrm{~g} / \mathrm{kg}$ body weight in Cirsium japonicum $0.5 \mathrm{mg} / \mathrm{kg}$ group; 1.15 $\pm 0.08 \mathrm{~g} / \mathrm{kg}$ body weight in Cirsium japonicum $5 \mathrm{mg} / \mathrm{kg}$ group. These results revealed that ovariectomy procedure itself alter the uteri weight. Cirsium japonicum increased uterine weight as did E2 (Fig. 3). These results confirm that Cirsium japonicum contains estrogenic effect in vivo as well as in vitro we showed in Figure 1.

\section{Cirsium japonicum extracts effect the serum lipid profile}

We have studied the effects of Cirsium japonicum on serum lipid profile (Table I). Ovariectomy elevated serum total cholesterol levels and E2 supplementation significantly lowed cholesterol levels. E2, Cirsium japonicum extracts $0.5 \mathrm{mg} / \mathrm{kg}$ and Cirsium japonicum extracts $5 \mathrm{mg} /$ $\mathrm{kg}$ induced significant reduction in TC (total cholesterol) (51\%, $41 \%$ and $17 \%$, respectively), LDLC/TC $(43 \%, 19 \%$ and $22 \%$, respectively), TC/HDLC (15\%, $18 \%$ and $10 \%$,

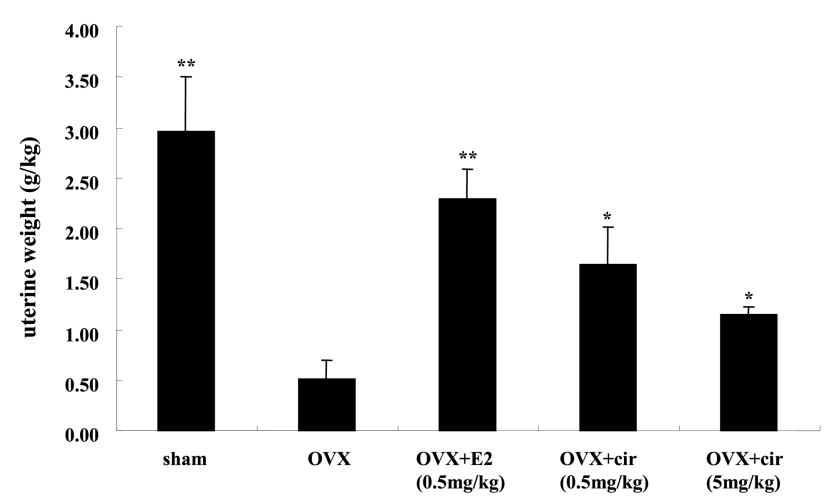

Fig. 3. Effect of Cirsium japonicum on weight of the uterus. Uteri were isolated 5 weeks after oral injection and measured. Treat groups are indicated in the figure. The asterisk * and ${ }^{*}$ shows a statistically significant difference from control at $\mathrm{p}<$ 0.05 and 0.001 . respectively) and LDLC/HDLC (48\%, 29\% and 32\%, respectively) compared to control. Interestingly Cirsium japonicum groups decreased triglycerides (TG) level whereas E2 groups significantly $(P<0.05)$ increased $T G$ level.

\section{DISCUSSION}

Phytoestrogens are secondary metabolites that are produced in a wide variety of plants and modulate the actions of endogenous estrogens, usually by binding to ER (Harris et al., 2005; Setchell, 1998). Phytoestrogens can act as partial ER agonists or antagonists. Estrogen action at target cells is mediated through distinct estrogen receptor $\alpha$ and $\beta$ isoforms (Kuiper et al., 1998). The binding pattern to the two ER subtypes, ER $\alpha$ and ER $\beta$, may vary among phytoestrogens (Kuiper et al., 1998). The broad classes of phytoestrogenic compounds include isoflavones, coumestans, ligans, and stilbens (Harris et al., 2005; Cornwell et al., 2004; Kurzer et al., 1997). Clinical trials showed that dietary isoflavones improved systemic arterial compliance in men and postmenopausal women, increased plasma nitrite/nitrate, decreased endothelin-1 levels, and increased brachial artery flow-mediated dilation (Teede et al., 2003; Squadrito et al., 2003). The U.S. Food and Drug Administration has endorsed the benefits of soy-based food products in lowering arterial blood pressure and oxidative stress in human subjects with mild to moderate hypertension (Hodgson et al., 1999; Rivas et al., 2002). In addition, a recent report showed that dietary soy protein leads to increased antioxidant, endothelial nitric oxide synthase gene expression and protected cancers, resulting in improved endothelial function in vitro, and reduced blood pressure in vivo in aging male rats (Mahn et al., 2005). Chinese traditional medicine has become increasingly popular and widely used over recent years. Thus, the cellular mechanisms of the herbal materials are of great interest both for ensur-

Table I. Effects of ovariectomy, estrogen and the Cirsium japonicum extracts on TG, TC, HDL-C/TC, LDL-C/TC and HDLC/LDL-C.

\begin{tabular}{cccccc}
\hline Treatment & TG & TC & LDLC/TC & HDLC/TC & LDLC/HDLC \\
\hline sham & $37.5 \pm 10.3$ & $97.48 \pm 21.5$ & $0.200 \pm 0.08$ & $0.499 \pm 0.22$ & $0.407 \pm 0.04$ \\
con & $48.13 \pm 19.39$ & $129.4 \pm 35.83$ & $0.285 \pm 0.12$ & $0.487 \pm 0.16$ & $0.571 \pm 0.06$ \\
E2 $(0.5 \mathrm{mg} / \mathrm{kg})$ & $106.05 \pm 36.19^{*}$ & $55 \pm 21.98^{*}$ & $0.164 \pm 0.07$ & $0.540 \pm 0.10$ & $0.294 \pm 0.08$ \\
cir $(0.5 \mathrm{mg} / \mathrm{kg})$ & $26.78 \pm 7.73$ & $76.3 \pm 17.9^{*}$ & $0.230 \pm 0.06$ & $0.575 \pm 0.16$ & $0.400 \pm 0.02$ \\
cir $(5 \mathrm{mg} / \mathrm{kg})$ & $33.88 \pm 12.52$ & $107.13 \pm 12.11$ & $0.222 \pm 0.09$ & $0.553 \pm 0.19$ & $0.244 \pm 0.04$ \\
\hline
\end{tabular}

All data are expressed as mean \pm SEM. The asterisk *shows a statistically significant difference from control group at $p<0.05$. 
ing safety and efficacy.

Our study showed that feeding Cirsium japonicum extracts resulted in significant improvements in total cholesterol, TG, LDL cholesterol, and cholesterol-to- HDL ratio. Other reports also have demonstrated that the soy phytoestrogen reduced insulin resistance, improved glycemic control, and reduced total cholesterol primarily through a reduction in LDL cholesterol, leading to an improvement in the ratio of total cholesterol to HDL cholesterol (Jayagopal et al., 2002). However the mechanism of the lipid-lowering effects of phytoestrogen through ER is not clear. We studied the effects of a water extract of Cirsium japonicum on lipid profile to provide scientific background for using Cirsium japonicum for vascular symptoms related to menopausal decrease in E2. Cirsium japonicum at $0.5 \mathrm{mg} / \mathrm{kg}$ showed uterotropic effect and lowered TC, LDLC/TC, and LDLC/HDLC as did E2. Cirsium japonicum as phytoestrogen produced positive effects on the lipid profile of ovariectomized rats. However, Cirsium japonicum at $5 \mathrm{mg} / \mathrm{kg}$ concentration did not show enhanced in vivo activity compared to $0.5 \mathrm{mg} / \mathrm{kg}$. We do not clearly understand the phenomena but it may be due to other components antagonizing E2 activity present at low concentration only reveal its activity at higher concentration of Cirsium japonicum. Further studies identifying the active components responsible for the estrogenic effects will improve our understanding of the clinical applications of Cirsium japonicum.

\section{ACKNOWLEDGMENTS}

This work was supported by grants from the Rural Development Administration to Y.J.L.

\section{REFERENCES}

Colacurci, N., Chiàntera, A., Fornaro, F., de Novellis, V., Manzella, D., Arciello, A., Chiàntera, V., Improta, L. and Paolisso, G. (2005). Effects of soy isoflavones on endothelial function in healthy postmenopausal women. Menopause. 12, 299-307.

Coope, J. and Marsh, J. Can we improve compliance with long term HRT? (1992). Maturitas. 15, 151-158.

Cornwell, T., Cohick, W. and Raskin, I. (2004). Dietary phytoestrogens and health. Phytochemistry. 65, 995-1016.

Deroo, B. J. and Korach, K. S. (2006). Estrogen receptors and human disease. J. Clin. Invest. 116, 561-70.

Eisenberg, D. M., Davis, R. B., Ettner, S. L., et al. (1998). Trends in alternative medicine use in the United States, 1990-1997. JAMA. 280, 1569-1575.

El-swefy, S. E., Ali, S. I., Asker, M. E. and Mohamed, H. E. (2002). Hyperhomocysteinemia and cardiovascular risk in female ovariectomized rats role of folic acid and hormone replacement therapy. Pharm. Pharmacol. 54, 391-397.

Ganzera, M., Pöcher, A. and Stuppner, H. (2005). Differentiation of Cirsium japonicum and $C$. setosum by TLC and HPLC-MS. Phytochem. Anal. 16, 205-209.

Gehm, B. D., McAndrews, J. M., Chien, P. Y. and Jameson, J. L. (1997). Resveratrol, a polyphenolic compound found in grapes and wine, is an agonist for the estrogen receptor. Proc. Natl. Acad. Sci. USA. 94, 14138-14143.

Glazier, M. G. and Bowman, M. A. (2001). A review of the evidence for the use of phytoestrogens as a replacement for traditional estrogen replacement therapy. Arch Intern Med. 161, 1161-72.

Harris, D. M., Besselink, E., Henning, S. M., Go, V. L. W. and Heber, D. (2005). Phytoestrogens induce differential estrogen receptor alpha- or beta-mediated responses in transfected breast cancer cells. Exp. Biol. Med. 230, 558-568.

Hodgson, J. M., Puddey, I. B., Beilin, L. J., Mori, T. A., Burke, V., Croft, K. D. and Rogers, P.B. (1999). Effects of isoflavonoids on blood pressure in subjects with high-normal ambulatory blood pressure levels: a randomized controlled trial, Am. J. Hypertens. 12, 47-53.

Http://en.wikipedia.org/wiki/cirsium

Http://en.wikipedia.org/wiki/Estrogen

Jayagopal, V., Albertazzi, P., Kilpatrick, E. S., Howarth, E. M., Jennings, P. E., Hepburn, D. A. and Atkin, S. L. (2002). Beneficial effects of soy phytoestrogen intake in postmenopausal women with type 2 diabetes. Diabetes Care. 25, 1709-1714.

Kuiper, G. G., Lemmen, J. G., Carlsson, B., Corton, J. C., Safe, S. H., van der Saag, P. T., van der Burg, B. and Gustafsson, J. A. (1998). Interaction of estrogenic chemicals and phytoestrogens with estrogen receptor $\beta$. Endocrinology. 139, 4252-4263.

Kurzer, M. S. and Xu, X. (1997). Dietary phytoestrogens, Annu Rev Nutr. 17, 353-381.

Lee, W. B., Kwon, H. C., Cho, O. R., Lee, K. C., Choi, S. U., Baek, N. I. and Lee, K. R. (2002). Phytochemical constituens of Cirsium setidens Nakai and their cytotoxicity against human cancer cell lines. Arch. Pharm. Res. 25, 628-635.

Mahn, K., Borras, C., Knock, G. A., Taylor, P., Khan, I. Y., Sugden, D., Poston, L., Ward, J. P., Sharpe, R. M., Vina, J., Aaronson, P. I. and Mann, G. E. (2005). Dietary soy isoflavone induced increases in antioxidant and eNOS gene expression lead to improved endothelial function and reduced blood pressure in vivo. FASEB J. 19, 1755-1757.

Park, M. K., Rhyu, M. R., Yoon, B. K., Kwon, H. Y., Jang. S., Lee, Y. J. (2008). Modulation of the genomic estrogen receptor pathway by water extracts of Cirsium japonicum. Arch Pharm Res. 31, 225-30.

Ravnikar, V. A. Compliance with hormone replacement therapy. (1987). Am J Obstet Gynecol. 156, 1332-1336.

Rivas, M., Garay, R. P., Escanero, J. F., Cia, P. Jr., Cia, P. and Alda, J. O. (2002). Soy milk lowers blood pressure in men an women with mild to moderate hypertension. J. Nutr. 132, 1900-1902.

Setchell, K. D. (1998). Phytoestrogens: the biochemistry, physiology, and implications for human health of soy isoflavones. Am. J. Clin. Nutr. 68, 1333S-1346S. 
Squadrito, F., Altavilla, D., Crisafulli, A., Saitta, A., Cucinotta, D., Morabito, N., D’Anna, R., Corrado, F., Ruggeri, P., Frisina. and Squadrito, G. (2003). Effect of genistein on endothelial function in postmenopausal women: a randomized, doubleblind controlled study. Am. J. Med. 114, 470-476.

Teede, H. J., McGrath, B. P., DeSilva, L., Cehun, M., Fassoulakis, A. and Nestel, P. J. (2003). Isoflavones reduce arterial stiffness: a placebo-controlled study in men and postmenopausal women. Arterioscler. Thromb. Vasc. Biol. 23, 10661071.

Yim, S. H., Kim, H. J. and Lee, I. S. (2003). A polyacetylene and flavonoids from Cirsium rhinoceros. Arch. Pharm. Res. 26, 128-131. 